\title{
Dielectric Constant and Emissivity of Forest Soil Samples at Microwave Frequency
}

\author{
C.B. Patil ${ }^{1 *}$, P.R. Chaudhari ${ }^{2}$ \\ ${ }^{1}$ Z B Patil College Dhule, North Maharashtra University, Jalgaon, India \\ ${ }^{2}$ Dept. of electronics, Z B Patil College Dhule, North Maharashtra University, Jalgaon, India \\ *Corresponding Author: chhaya26nov@ rediffmail.com, Tel.: 9604563516
}

Available online at: www.isroset.org

Accepted: 09/Aug/2018, Online: 31/Aug/2018

\begin{abstract}
The measurement of dielectric constant and emissivity for forest soil samples at 9.6GHz microwave frequency by using waveguide cell method. The values of emissivity of soil samples are measured by using respective dielectric constant. The estimations of emissivity are made with incidence angles from $0^{0}$ to $90^{0}$ for vertical polarization. The result shows that the emissivity of soil depends on microwave frequency in x-band region and angle of incidence. Also the change in emissivity for vertical polarization occurs at higher angles of incidence and at change over angle the emissivity reaches to unity.
\end{abstract}

Keywords - Dielectric constant, emissivity, forest soils, microwave frequency, vertical polarization.

\section{INTRODUCTION}

The study of earth's surface is important for remote sensing applications. The electrical properties like dielectric constant and emissivity of the objects on the earth surface like soil samples are fundamental significance in microwave remote sensing. In microwave frequency region, it is observed that dielectric constant increases with increase in moisture content slowly up to transition moisture then it increases rapidly with increase in moisture content. Also found that emissivity decreases with increase in moisture content [1].This property of emission of electromagnetic energy is called emissivity. Emissivity is the important parameter, which provides information about soil. The emissivity of soil also varies with different moisture content. Knowledge of emissivity of soil is useful for the efficient use of soil [2].In microwave frequency region; the dielectric constant of soil is a function of its moisture content [3].

Because of absorption of minute amount of moisture from atmosphere, the dielectric constant and emissivity become frequency dependent. In this paper dielectric constant and emissivity for vertical polarization are measured for six forest soil samples at $9.6 \mathrm{GHz}$ microwave frequency in $\mathrm{X}$ band region.

\section{RELATED WORK}

\subsection{Measurement of Dielectric Constant}

The dielectric constant of six forest soil samples are S5, S6 S7, S8 S9 and S10have been measured at $9.6 \mathrm{GHz}$ microwave frequency in $\mathrm{X}$ - band region. The $\mathrm{X}$-band microwave test bench shown in Fig.1 was used to measure dielectric constant of soil samples. Soil samples were shaped according to the dimensions of rectangular waveguide i.e. with $2.286 \mathrm{~cm} \times 1.016 \mathrm{~cm}$. The waveguide cell method was used to measure dielectric constant.

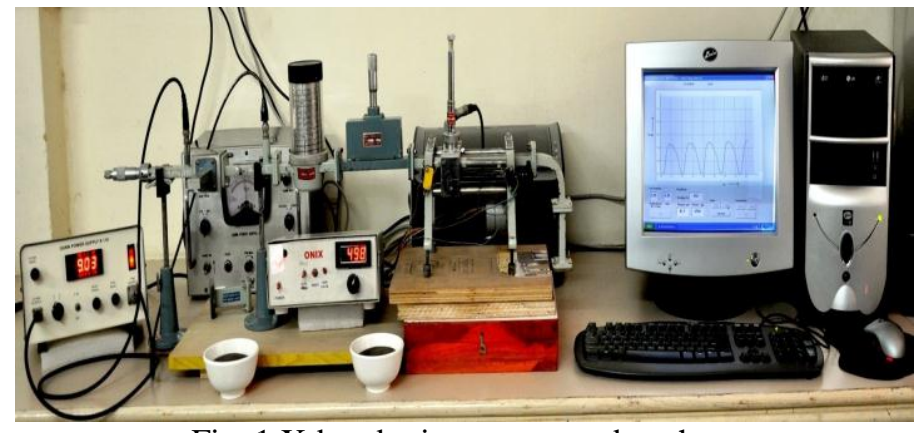

Fig. $1 \mathrm{X}$-band microwave test bench

The equation of dielectric constant is,

$$
\varepsilon^{\prime}=\frac{\left[(\mathrm{a} / \pi)^{2}\left(\mathrm{x} / \mathrm{l}_{\varepsilon}\right)^{2}\right]+1}{\left(2 \mathrm{a} / \lambda_{\mathrm{g}}\right)^{2}+1}
$$

Where $\mathrm{x}$ is found by following equation,

$$
\tan x / x=\frac{\tan \left[\beta\left(l_{\varepsilon}+D_{R}-D\right)\right]}{\beta 1_{\varepsilon}}
$$

Where, $\beta=\left(2 \pi / \lambda_{\mathrm{g}}\right) \varepsilon^{\prime}=$ dielectric constant, $\beta=$ phase shift, $\mathrm{a}=$ width of wavelength, $1_{\varepsilon}=$ sample length, $\lambda \mathrm{g}=$ guide wavelength,

$\left(D_{R}-D\right)=$ shift in minima, $D_{R}=$ minima for without sample, $\mathrm{D}=$ minima for with sample.

\subsection{Estimation of Emissivity}

The values of emissivity of forest soil samples are estimated for angle of incidence from $0^{0}$ to $90^{0}$ These values are 
estimated for vertical polarization by using already measured dielectric constant at three microwave frequencies [4].

The equation of emissivity $\mathrm{e}_{\mathrm{p}}(\theta)$ is

$\mathrm{e}_{\mathrm{p}}(\theta)=1-\mathrm{r}_{\mathrm{p}}(\theta)=1-\left|\mathrm{R}_{\mathrm{p}}(\theta)\right|$

Where, $R_{p}(\theta)$ is the Fresnel reflection coefficient

For vertical polarization,

$\mathrm{e}_{\mathrm{p}}(\theta)=1-\frac{\varepsilon^{\prime} \cos \theta-\left(\varepsilon^{\prime}-\sin ^{2} \theta\right)^{1 / 2}}{\varepsilon^{\prime} \cos \theta+\left(\varepsilon^{\prime}-\sin ^{2} \theta\right)^{1 / 2}}$

Where $\theta$ is the angle of incidence and $\varepsilon^{\prime}$ is the dielectric constant.

\section{RESULTS AND DISCUSSION}

3.1 Variation of dielectric constant with moisture content. Fig. 2 shows variation of dielectric constant with respect to moisture content for all forest soil samples under study.

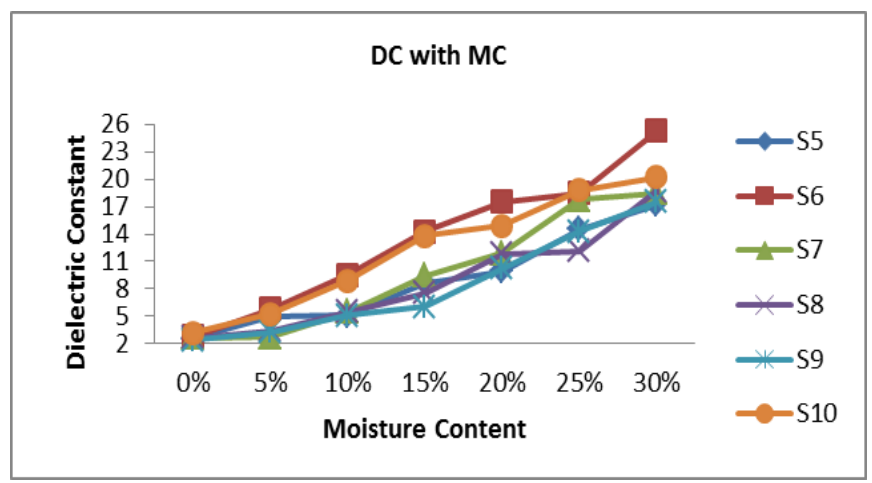

Fig. 2 Variation of DC with MC

From this graph, observed that for all soil samples dielectric constant increases with increases in moisture content

3.2 . Variation of Emissivity with Angle of Incidence for Vertical Polarization at $9.6 \mathrm{GHz}$ Frequency.

The studies of emission characteristics of dry and wet soils have been carried by Calla and Sharma [5] and Calla et al. [6]. They studied the emissivity of dry and wet soils from different regions of India at different frequencies and different angles of incidence. Fig. 3(a-f) shows the variation of emissivity (vertical polarization) for six forest soil samples with angle of incidence at $9.6 \mathrm{GHzfrequency.It}$ is observed that there is a same trend in the variation of emissivity with angle of incidence with various moisture content for all forest soil samples.
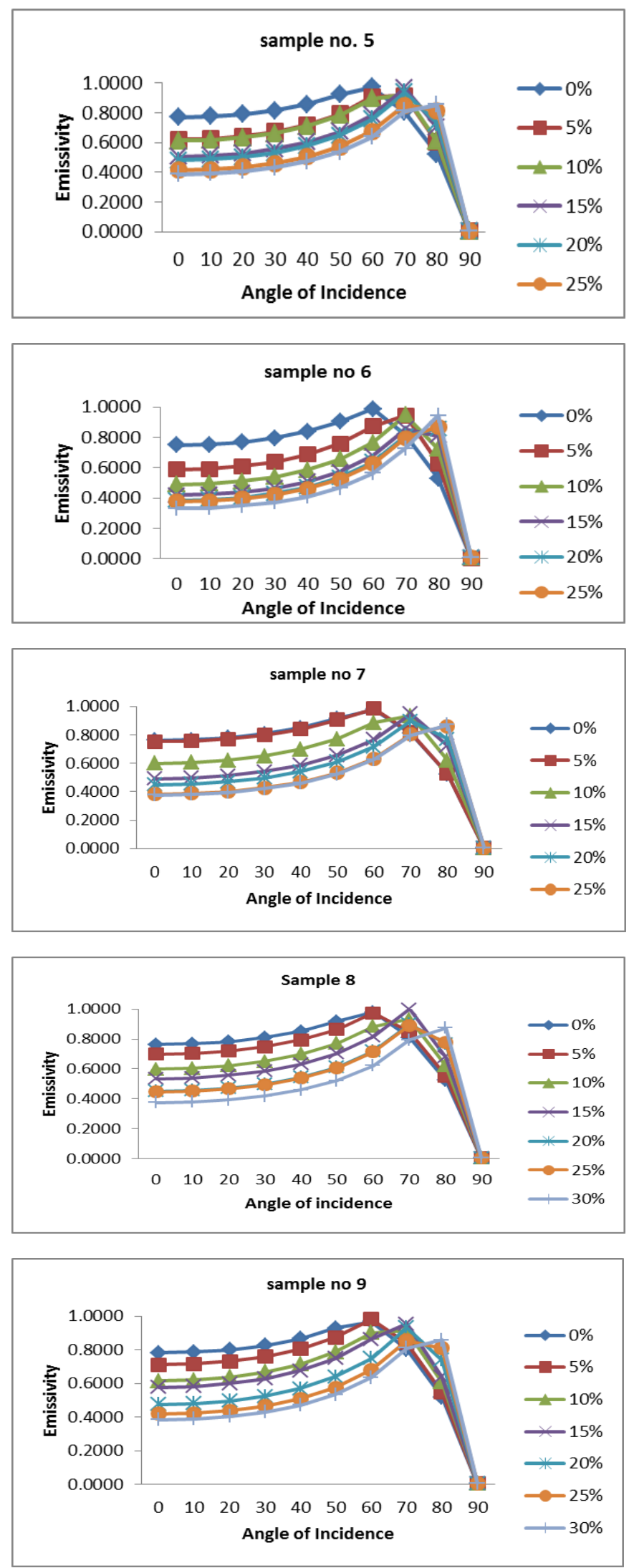


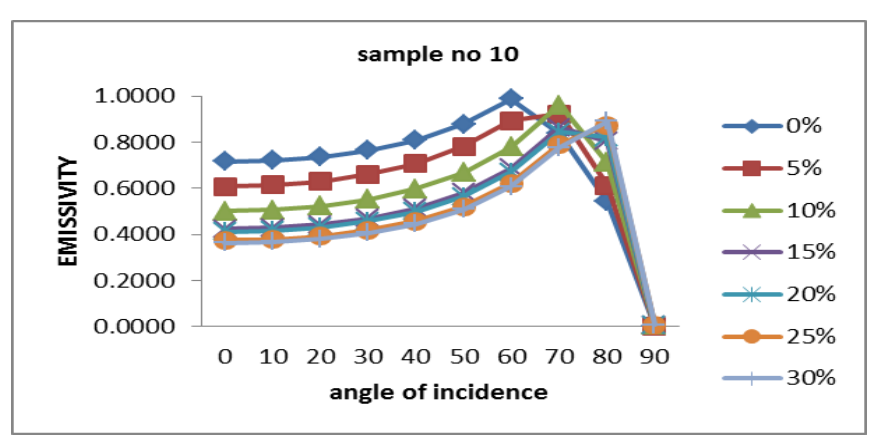

In fig 3(a-f)observed that for all soil samples, at $9.6 \mathrm{GHz}$ frequency, up to change over angle there is significant difference between the values of emissivity. Beyond this the emissivity at all frequencies will try to close with each other and at last at it reaches to about 0.9 at $90^{\circ}$.

From the results and discussion we have concluded the following points.

- At a given frequency the trend of variation of emissivity with angle of incidence in vertical polarization, for all forest soils samples under study, is almost the same.

- The value of emissivity for vertical polarization, at $9.6 \mathrm{GHz}$ frequency, initially increases with angle of incidence and then after a change over angle, it starts decreasing. This change over angle lies between $50^{\circ}$ to $80^{\circ}$.

- In vertical polarization the change in emissivity occurs at higher angle of incidence and hence it is suitable to study emissivity behavior at these angles.

- For all soil samples at 9.6 GHz frequency, the value of dielectric constant increases with increase in moisture content.

Such study of emissivity of forest soil under ambient atmospheric conditions forms the basis for detecting and mapping areas containing potential deposits of sources of forest soil using remote sensing techniques. It also provides information for designing of passive microwave sensors in microwave remote sensing.

\section{ACKNOWLEDGMENT}

The authors are very much grateful to UGC, New Delhi, and Principal,Z.B. PatilCollege,Dhule for providing a facility of microwave bench to our Research Laboratory through CPE scheme. The authors are also very much thankful to Prof. OPN Calla for his kind suggestions during the course of this research work.

\section{REFERENCES}

[1]. M. D. Diware, S. B. Nahire, Sushant Deshmukh, "Complex Dielectric Behaviour of Soil From Nasik Region at X-Band
MF,"Indian Journal of Scientific and Research Publications, Vol 6.Dec 2016 Radio and Space Physics, vol.33,321-328,2004.

[2]. OPN Calla and R. K. Singh," Emission Characteristics of Dry and Wet Loamy sand Soil Layered Packed at Microwave Frequency," Indian Journal of Radio and Space Physics, vol 31. 285-292 June 2002.

[3]. H. C. Chaudhary and V. J. Shinde,"Dielectric Properties of Soils atX-band Microwave Frequencies,"Indian J. ofRadio and Space Phys.,vol. 50, pp. 64-66, Jan 2012.

[4]. OPN Calla, A. Baruah, B. Das, K. P. Mistra, M. Kalita, and S. S. Haque, "Emission and scattering behavior of dry soils from northest India," Indian J. ofRadio and Space Phys.,vol. 33, pp. 321-328, 2004.

[5]. O. P. N. Calla and Sharma Santanu, "Study of scattering behavior of dry and wet soil with undulating surface at microwave frequencies," Indian Journal of Radio and Space Physics, vol 30. 332-336 2001,.

[6]. O. P. N. Calla, Baruah A., Das B., Mishra K. P., Kalita M., and Haque S. S., "Emission and scattering behavior of dry soils from northest India," Indian Journal of Radio and Space Physics, vol.33,321-328,2004.

[7]. Chhaya B. Patil and P. R. Chaudhari, "Dielectric Constant and Emissivity of rock samples at Microwave Frequencies,"InternationalJournal of Innovative Research in Science, Engineering and Technology

\section{AUTHORS PROFILE}

Mrs. C B Patil pursed B.Sc., M.Sc., and M.Phil. in Physics from North Maharashtra University, jalgaon, Maharashtra in 2004, 2006, $\& 2009$. He is currently working on her Ph. D. course in physics North Maharashtra University, jalgaon, Maharashtra since 2012. She has published 03 research papers in reputed international journals and conferences.

Mr. P. R. Chaudhari pursed M. Sc. in Physics from Poona University, Pune in 1983 and Ph.D. from BAMU, Aurangabad in 1994. He is currently working as Associate Professor in Department of Physics, Z. B. Patil College, Dhule since 1983. He has published more than 40 research papers in reputed international journals and conferences. His main research work focuses on Agrophysics using Microwave Techniques. He has 35 years of teaching experience and 20 years of research experience. 